\title{
Smokeless Tobacco
}

National Cancer Institute

\section{Source}

National Cancer Institute. Smokeless Tobacco. NCI Thesaurus. Code C892.

Tobacco that is not smoked but used in another form such as chewing tobacco or snuff. 